\title{
Tumor Thickness of Oral Lesions with and without Metastasis in Neck
}

\author{
Yasir Maqsood ${ }^{1}$, Mukhtar Ibrahim $^{2}$, Shaheen Malik ${ }^{3}$
}

\section{ABSTRACT}

Objective: To determine the association of thickness of tumor of oral lesions with and without metastasis in neck based on computerized tomography (CT) scan.

Methods: A retrospective study was conducted among patients having age $>18$ years of either gender diagnosed with oral squamous cell carcinoma (SCC). Moreover, patients with buccal mucosa and tongue malignant tumor were also included. CT scan was performed on all patients and tumor thickness in anteroposterior, transverse, and craniocaudal positions were measured.

Results: A total of 119 patients were included. The mean age of the patients was $46.97 \pm 11.79$ years. Male preponderance was found to be higher 102 (85.7\%) than that of females 17 (14.3\%). The mean anterioposterior thickness level was significantly higher in right side of oral cavity as compared to left side (4.39 \pm 2.12 vs $3.52 \pm 1.56$, p-value 0.015$)$. Moreover, mean transverse dimension was found significantly higher among patients in whom post tongue was involved as compared to those among which post tongue was not involved ( $5.05 \pm 1.56$ vs $2.64 \pm 1.78$, p-value 0.009). Metastasis was significantly higher among patients with right side of oral tumor as compared to those with left side of oral tumor (p-value 0.043).

Conclusion: Metastasis of anterioposterior thickness level was significantly higher among patients with right side of SCC while transverse dimension was found significantly higher among patients in whom post tongue was involved.

Key words: CT scan, lymph nodes, oral tumor thickness, neck metastasis.

How to cite this article: Maqsood Y, Ibrahim M, Malik S. Tumor thickness of oral lesions with and without metastasis in neck. J Dow Uni Health Sci. 2018; 12(3): 109-113.

\section{INTRODUCTION}

Early diagnosis of neck metastasis is vital for better prognosis. ${ }^{1,2}$ Several studies have reported association of neck metastasis with oral tumors. Moreover, decrease survival is also noted in such patients. ${ }^{3-5}$ Among all diagnostic

1. Hamdard College of Medicine \& Dentistry Karachi, Pakistan.

2. National Medical Centre Karachi, Pakistan.

3. Baqai Medical University Karachi, Pakistan.

\section{Correspondence:}

Dr. Yasir Maqsood,

Hamdard College of Medicine \&

Dentistry Karachi, Pakistan.

Email: yasirmaqsoodent@gmail.com modalities, computed tomography (CT) scan and magnetic resonance imaging (MRI) are advanced modalities which not only helps in accurate diagnosis but also defines precise local or regional invasion of tumors. ${ }^{6-8}$ In addition, gamma probes are also recently advanced technique recommended by clinicians to explore occult metastasis in neck with limited success. ${ }^{9,10}$

The CT scan of neck with contrast is a reliable and widely available modality for the diagnosis of lymph nodes in neck. ${ }^{11,12}$ The accurate and cost-effective diagnosis of lymph nodes in neck among oral tumor patients is essential for early diagnosis. This study was conducted with aim to evaluate the thickness of tumor of oral lesions with and without metastasis in neck based on computerized tomography (CT) scan. 


\section{METHODS}

A prospective study was conducted at Hamdard University Hospital, Karachi, from June 2015 to June 2017 among 119 patients with oral tumor. Requirement of informed consent was waived as all data was collected from medical record. All patients having age $>18$ years of either gender diagnosed with oral SCC and malignant tumor of buccal mucosa and tongue were included while patients having allergy with intravenous contrast and/or pregnant patients were excluded. The CT scan was performed and tumor thickness in anteroposterior, transverse, and craniocaudal positions were measured. In addition to this, site of SCC of oral cancer, thickness of tumor, tumor stage, and cervical lymph nodes involvement were also measured. The guidelines given by American Joint Committee on Cancer (AJCC) were used for staging of tumors. ${ }^{13}$

Statistical package for social sciences version 22 was used for the purpose of statistical analysis. Independentt-test was applied to see the mean difference tumor thickness level with respect to baseline characteristics. Moreover, chi-square test was applied to comparison tumor thickness with baseline characteristics. P-value $<0.05$ was taken as significant.

\section{RESULTS}

Out of total 119 patients, 59 (49.6\%) patients were presented with $\leq 50$ years of age while 60 (50.4\%) patients were presented with $>50$ years of age (mean age $46.97 \pm 11.79$ years). Male preponderance was found to be higher $102(85.7 \%)$ than that of females $17(14.3 \%)$. There were $68(57.1 \%)$ patients with right oral tumor while 51 (42.9\%) with left side of tumor. Cheek and/or buccal mucosa were affected in 51 (42.9\%) patients. There were 57 (47.9\%) patients with lateral margin of tongue whereas dorsum tongue was involved in 9 (7.6\%) patients. Floor of mouth in $6(5 \%)$ and post tongue in $4(3.4 \%)$ patients reported. Comparison of age and gender with respect to baseline characteristics is shown in Table 1.

\section{Table 1: Comparison of age and gender with respect to baseline characteristics $(n=119)$}

\begin{tabular}{|c|c|c|c|c|c|}
\hline & \multicolumn{3}{|c|}{ Age, years } & \multicolumn{2}{|l|}{ Gender } \\
\hline & $n(\%)$ & $\leq 45$ & $>45$ & Male $(n=102)$ & Female $(\mathrm{n}=17)$ \\
\hline \multicolumn{6}{|c|}{ Side of SCC oral cavity } \\
\hline Right & 68 & $40(58.8)$ & $28(41.2)$ & $59(86.8)$ & $9(13.2)$ \\
\hline Left & 51 & $19(37.3)$ & $32(62.7)$ & $43(84.3)$ & $8(15.7)$ \\
\hline \multicolumn{6}{|c|}{ Cheek/Buccal/Mucosa } \\
\hline Yes & 51 & $19(37.3)$ & $32(62.7)$ & $41(80.4)$ & $10(19.6)$ \\
\hline No & 68 & $40(58.8)$ & $28(41.2)$ & $61(89.7)$ & $7(10.3)$ \\
\hline \multicolumn{6}{|c|}{ Tongue involvement } \\
\hline Lateral margin & 57 & $37(64.9)$ & $20(35.1)$ & $52(91.2)$ & $5(8.8)$ \\
\hline Dorsum & 9 & $6(66.7)$ & $3(33.3)$ & $9(100)$ & $0(0)$ \\
\hline \multicolumn{6}{|l|}{ Floor of mouth } \\
\hline Yes & 6 & $0(0)$ & $6(100)$ & $4(66.7)$ & $2(33.3)$ \\
\hline No & 113 & $59(52.2)$ & $54(47.8)$ & 98 (86.7) & $15(13.3)$ \\
\hline \multicolumn{6}{|l|}{ Post tongue } \\
\hline Yes & 4 & $0(0)$ & $4(100)$ & $4(100)$ & $0(0)$ \\
\hline No & 115 & $59(51.3)$ & $56(48.7)$ & $98(85.2$ & $17(14.8)$ \\
\hline
\end{tabular}

n: Number, SCC: Squamous Cell Carcinoma 
The mean anterioposterior thickness level was significantly higher in right side of oral cavity as compared to left side $(4.39 \pm 2.12$ vs 3.52 \pm 1.56 , p-value 0.015). Moreover, mean transverse dimension was found significantly higher among patients in whom post tongue was involved as compared to those among which post tongue was not involved (5.05 \pm 1.56 vs $2.64 \pm 1.78$, p-value 0.009 ). (Table 2 )

Metastasis was significantly higher among patients with right sided oral tumor as compared to those with left sided oral tumor (p-value 0.043). (Table 3)

Table 2: Difference of tumor thickness level with respect to baseline characteristics $(n=119)$

\begin{tabular}{|c|c|c|c|c|c|c|c|}
\hline & \multicolumn{3}{|c|}{ Anterioposterior } & \multicolumn{2}{|c|}{ Transverse dimension } & \multicolumn{2}{|c|}{ Craniocaudal } \\
\hline & $\begin{array}{l}\mathrm{n} \\
(\%)\end{array}$ & Mean \pm SD & p- value ${ }^{\dagger}$ & Mean \pm SD & p- value ${ }^{\dagger}$ & Mean \pm SD & p-value ${ }^{\dagger}$ \\
\hline \multicolumn{8}{|c|}{ Side of SCC oral cavity } \\
\hline Right & 68 & $4.39 \pm 2.12$ & & $2.76 \pm 2.02$ & & $4.16 \pm 2.69$ & \\
\hline Left & 51 & $3.52 \pm 1.56$ & 0.015 & $2.67 \pm 1.53$ & 0.791 & $4.01 \pm 1.96$ & 0.763 \\
\hline \multicolumn{8}{|c|}{ Cheek/Buccal/Mucosa } \\
\hline Yes & 51 & $4.37 \pm 2.09$ & & $2.94 \pm 2.13$ & & $4.72 \pm 2.84$ & \\
\hline No & 68 & $3.76 \pm 1.78$ & 0.091 & $2.56 \pm 1.54$ & 0.254 & $3.63 \pm 1.93$ & 0.54 \\
\hline \multicolumn{8}{|c|}{ Tongue involvement } \\
\hline Lateral margin & 57 & $3.87 \pm 1.76$ & & $2.52 \pm 1.46$ & & $3.43 \pm 1.59$ & \\
\hline Dorsum & 9 & $4.97 \pm 1.61$ & 0.083 & $2.65 \pm 1.85$ & 0.811 & $4.10 \pm 2.45$ & 0.282 \\
\hline \multicolumn{8}{|l|}{ Floor of mouth } \\
\hline Yes & 6 & $2.56 \pm 0.98$ & & $2.31 \pm 1.08$ & & $4.31 \pm 2.43$ & \\
\hline No & 113 & $4.10 \pm 1.95$ & 0.059 & $2.74 \pm 1.85$ & 0.559 & $4.08 \pm 2.42$ & 0.864 \\
\hline \multicolumn{8}{|l|}{ Post tongue } \\
\hline Yes & 4 & $4.80 \pm 2.07$ & & $5.05 \pm 1.56$ & & $5.91 \pm 3.01$ & \\
\hline No & 115 & $3.99 \pm 1.94$ & 0.418 & $2.64 \pm 1.78$ & 0.009 & $4.01 \pm 2.35$ & 0.125 \\
\hline
\end{tabular}

${ }^{\dagger}$ Independent t-test applied, $\mathrm{p}$-value $<0.05$ taken as significant

n: number, SCC: Squamous Cell Carcinoma

Table 3: Comparison of tumor thickness with baseline characteristics $(n=119)$

\begin{tabular}{|c|c|c|c|c|c|c|c|c|c|}
\hline & \multicolumn{2}{|c|}{ Anterioposterior } & \multirow[b]{2}{*}{$\begin{array}{c}\text { p- } \\
\text { value }^{\dagger}\end{array}$} & \multicolumn{2}{|c|}{ Transverse dimension } & \multirow[b]{2}{*}{$\begin{array}{c}\text { p- } \\
\text { value }^{\dagger}\end{array}$} & \multicolumn{2}{|c|}{ Craniocaudal } & \multirow[b]{2}{*}{$\begin{array}{c}\text { p- } \\
\text { value }^{\dagger}\end{array}$} \\
\hline & $\begin{array}{l}\text { Non- } \\
\text { metastasis }\end{array}$ & Metastasis & & $\begin{array}{l}\text { Non- } \\
\text { metastasis }\end{array}$ & Metastasis & & $\begin{array}{l}\text { Non- } \\
\text { metastasis }\end{array}$ & Metastasis & \\
\hline \multicolumn{10}{|c|}{ Side of SCC oral cavity } \\
\hline Right & $37(54.4)$ & $31(45.6)$ & & $56(82.4)$ & $2(17.6)$ & & $27(57.4)$ & $20(42.6)$ & \\
\hline Left & $37(72.5)$ & $14(27.5)$ & 0.043 & $41(80.4)$ & $10(19.6)$ & 0.785 & $19(57.6)$ & $14(42.4)$ & 0.991 \\
\hline \multicolumn{10}{|c|}{ Cheek/Buccal/Mucosa } \\
\hline Yes & $30(58.8)$ & $21(41.2)$ & & $41(80.4)$ & $10(19.6)$ & & $18(52.9)$ & $16(47.1)$ & \\
\hline No & $44(64.7)$ & $24(35.3)$ & 0.513 & $56(82.4)$ & 12 (17.6) & 0.785 & $28(60.9)$ & $18(39.1)$ & 0.478 \\
\hline \multicolumn{10}{|c|}{ Tongue involvement } \\
\hline Lateral margin & 35 (61.4) & $22(38.6)$ & & $47(82.5)$ & $10(17.5)$ & & $23(62.2)$ & $14(37.8)$ & \\
\hline Dorsum & $3(33.3)$ & $6(66.7)$ & 0.113 & $5(55.6)$ & $4(44.4)$ & 0.067 & $2(33.3)$ & $4(66.7)$ & 0.184 \\
\hline \multicolumn{10}{|l|}{ Floor of mouth } \\
\hline Yes & $6(100)$ & $0(0)$ & & $6(100)$ & $0(0)$ & & $2(50)$ & $2(50)$ & \\
\hline No & $68(60.2)$ & 45 (39.8) & 0.05 & $91(80.5)$ & $22(19.5)$ & 0.231 & $44(57.9)$ & $32(42.1)$ & 0.756 \\
\hline \multicolumn{10}{|l|}{ Post tongue } \\
\hline Yes & $2(50)$ & $2(50)$ & & $2(50)$ & $2(50)$ & & $2(50)$ & $2(50)$ & \\
\hline No & $72(62.6)$ & $43(37.4)$ & 0.609 & $95(82.6)$ & $20(17.4)$ & 0.099 & $44(57.9)$ & $32(42.1)$ & 0.756 \\
\hline
\end{tabular}

${ }^{\dagger}$ Chi-square test applied, p-value $<0.05$ taken as significant All data presented as number (\%) 


\section{DISCUSSION}

The finding of this study reported a significant difference in between anterioposterior tumor thickness level and side of oral cavity. Furthermore, transverse dimension and post tongue was also found to be significant. Mean tumor thickness at anterioposterior was significantly higher at right side of the oral cavity while transverse dimension was significantly higher among patients with post tongue involvement. Comparison on the basis of metastasis and non-metastasis also showed that metastasis in anterioposterior tumor thickness level was found to be higher among patients with right side of oral cavity as compared to the patients with left side of oral cavity involvement. This finding matched with a previous study from our region. ${ }^{14}$ The reason for higher prevalence of right of oral cavity may be due to the reason that in our region majority of the people are right-handed. For this reason, they might have an inclination for keeping pan and/or betel nut on the right side of oral cavity.

In this study, males were predominantly higher as compared to females. This finding is also in comparison to the previously study as well. ${ }^{15}$

Ahmed SQ et al in their study revealed that the odds of neck node metastasis in buccal SCC is 35.5 times higher for a tumor thickness more than equal to $2 \mathrm{~mm}$ and the odds of neck node metastasis in buccal SCC is 58\% lower for each centimeter decrease in tumor size. ${ }^{16}$

In our study, we have used CT scan with contrast. In a study conducted by Madana J et al, the tumor thickness measurement at CT scan was found closely related with histology. ${ }^{17}$ In contrary to above mentioned studies, Park JO et al in his study evaluated the diagnostic accuracy of MRI taking histopathological specimens as gold standard in diagnosing tumor size. ${ }^{18}$ The finding showed that the accessibility and the patient's compliance of CT scan is better when compared to MRI Scan. There were few limitations in this study. Firstly, our study failed to obtained data on the stages of tumor. Secondly, we have not evaluated the diagnostic accuracy of CT. Determination of diagnostic accuracy considering histopathology will also help in determining the information regarding elective neck dissection based on measurement of tumor thickness level. Lastly, this study was conducted retrospectively. Future multicenter studies are recommended which evaluates the association of oral tumor thickness with metastasis in neck prospectively at large scale.

\section{CONCLUSION}

Metastasis of anterioposterior thickness level was significantly higher among patients with right side of SCC while transverse dimension was found significantly higher among patients in whom post tongue was involved.

\section{REFERENCES}

1. Greenberg JS, El Naggar AK, Mo V, Roberts D, Myers JN. Disparity in pathologic and clinical lymph node staging in oral tongue carcinoma. Implication for therapeutic decision making. Cancer 2003; 98:508-15.

2. Teymoortash A, Werner JA. Current advances in diagnosis and surgical treatment of lymph node metastasis in head and neck cancer. Laryngorhinootologie 2012; 91:S102-22.

3. Shingaki S, Takada M, Sasai K, Bibi R, Kobayashi T, Nomura T. Impact of lymph node metastasis on the pattern of failure and survival in oral carcinomas. Am J Surg 2003; 185:278-84.

4. Ferlito A, Rinaldo A, Robbins KT, Leemans CR, Shah JP, Shaha AR, et al. Changing concepts in the surgical management of the cervical node metastasis. Oral Oncol 2003; 39:429-35.

5. Watkinson JC, Gilbert RW. Stell and Maran's textbook of Head and Neck Surgery and Oncology. Fifth edition 2012, chapter 34, published by Hodder Arnold ISBN-13 9781444172324 
6. Mancuso AA, Macen D, Rice D, Hanafee W. CT of Cervical Lymph Node Cancer. Am J Roentgenol 1981; 136:381-5.

7. Som PM. Detection of Metastasis in Cervical Lymph Nodes: CT and MR Criteria and Differential Diagnosis. Am J Roentgenol 1992; 158:961-9.

8. Hoang JK, Vanka J, Ludwig BJ, Glastonbury CM. Evaluation of Cervical Lymph Nodes in Head and Neck Cancer With CT and MRI: Tips, Traps, and a Systematic Approach. Am J Roentgenol 2013; 200:W17-W25.

9. Stoeckli SJ, Steinert H, Pfaltz M, Schmid S. Sentinel Lymph Node Evaluation in Squamous Cell Carcinoma of the Head and Neck . Otolaryngol Head Neck Surg 2001; 125:221-6.

10. Hart RD, Nasser JG, Trites JR, Taylor S, Bullock M, Barnes D. Sentinel Lymph Node Biopsy in N0 Squamous Cell Carcinoma of the Oral Cavity and Oropharynx. Arch Otolaryngol Head Neck Surg 2005; 131:34-8.

11. Joo YH, Hwang SH, Sun D, Cho KJ, Park JO, Kim MS. Relationships between Tumor Volume and Lymphatic Metastasis and Prognosis in Early Oral Tongue Cancer. Clin Exp Otorhinolaryngol 2013; 6:243-8.

12. Kimura Y, Sumi M, Sumi T, Ariji Y, Ariji E, Nakamura T. Deep extension from carcinoma arising from the gingiva: CT and MR imaging features. Am J Neuroradiol 2002; 23:468-72.
13. Edge SB, Compton CC. The American Joint Committee on Cancer: the 7th edition of the AJCC cancer staging manual and the future of TNM. Anns Surgical Oncology 2010;17:1471-4.

14. Khan SA, Zia S, Naqvi SU, Adel H, Adil SO, Hussain M. Relationship of Oral Tumor Thickness with the rate of lymph node metastasis in Neck based on CT Scan. Pak J Med Sci 2017; 33:353.

15. Bray F, Ren JS, Masuyer E, Ferlay J. Global estimates of cancer prevalence for 27 sites in the adult population in 2008. Int J Cancer 2013; 132:1133-45.

16. Ahmed SQ, Junaid M, Awan S, Choudhary MM, Kazi M, Masoom Aet al. Relationship of tumor thickness with neck node metastasis in buccal squamous cell carcinoma: an experience at a tertiary care hospital. Int Arch Otorhinolaryngol 2016; 21:1.

17. Madana J, Laliberte F, Morand GB, Yolmo D, Black MJ, Mlynarek AM, et al. Computerized tomography based tumorthickness measurement is useful to predict postoperative pathological tumor thickness in oral tongue squamous cell carcinoma. J Otolaryngol Head Neck Surg 2015; 44:18.49.

18. Park JO, Jung SL, Joo YH, Jung CK, Cho KJ, Kim MS. Diagnostic accuracy of magnetic resonance imaging (MRI) in theassessment of tumor invasion depth in ral/oropharyngeal cancer. Oral Oncol 2011; 7:38 1-6. 